\title{
The Research on Humanresource Development of Tencent-The HR Three Pillar Model
}

\author{
Zhenchuan Jiang1,2, Xun Gong1,3* \\ ${ }^{1}$ School of Economics and Management, Beijing Jiaotong University, Beijing, China \\ ${ }^{2}$ Graduate School of Lyceum of the Philippines University, Manila, Philippines \\ ${ }^{3}$ Beijing Center for Industrial Security and Development Research, Beijing, China \\ Email: jiangzc0810@163.com, *gongxun83@aliyun.com
}

How to cite this paper: Jiang, Z.C. and Gong, X. (2019) The Research on Humanresource Development of Tencent-The HR Three Pillar Model. Journal of Human Resource and Sustainability Studies, 7, $462-474$.

https://doi.org/10.4236/jhrss.2019.73030

Received: September 3, 2019

Accepted: September 20, 2019

Published: September 23, 2019

Copyright $\odot 2019$ by author(s) and Scientific Research Publishing Inc. This work is licensed under the Creative Commons Attribution International License (CC BY 4.0).

http://creativecommons.org/licenses/by/4.0/

\begin{abstract}
With the development of company, human resource has been increasingly important for a company, some research shows that human resource has positive correlation with company performance. Human capital value is one of the most important resource of a company. To satisfy requirements of the development of company and the expansion of business, paid dramatic attention has been to human resource department. In this paper, the human resource department of Tencent will be shown and analyzed. The HR three pillar model is practiced by Tencent and developed to new form. The development of human resource has been a significant requirement of Tencent to expand business and an important strategy to promote competitiveness.
\end{abstract}

\section{Keywords}

Tencent, Human Resource Development, Human Resource Management, HR Three Pillar

\section{The Problem and Its Background}

\subsection{Background of Problem and Statement}

With the development of economy and society, the competition between companies even countries has been increased sharply. Human resource has been increasingly important for companies; especially, some multinational companies realize that human capital is one of the most significant factors in competition. Recently, information update brings the era of Big Data. Human resource is still important in the field of management disciplines and faces in new opportunities and challenges [1]. The work of human resource in the enterprise gradually relies on the value development and utilization of data among the six modules of ${ }^{*}$ Correspondence author. 
Human Resources (HR), including human resource planning, recruitment and configuration, training and development, performance management, and compensation management. However, in the Big Data Era, how to utilize Human Resource Management (HRM) more effectively and make employees more skillful and satisfying has been paid attention by abundant scholar and companies [2].

Therefore, the problem of this paper is how Human Resource Development (HRD) of a company should be updated to follow the trend. And the author believes the HRD ought to adhere to innovation, in the process of enterprise development, to help the organization develop.

This paper may be beneficial to people and organization to realize the importance of HRD in the process of company developing. However, limitation of this paper is that the quantitative research is better to be involved.

\subsection{Objective of Study}

This paper will show organizational structure of HRD of a successful firm, Tencent and analyze how HRD can positively affect the company development. Tencent is a symbol of China internet company, and the HRD in Tencent is a miniature of the development of the organization. Therefore, Tencent is the selected case for this paper to represent the HRD. This paper introduces the process of HRD in Tencent, people can easily understand how Tencent's HRD satisfy the development of the company.

\subsection{Brief Introduction of Tencent}

Tencent is an internet-based technology and cultural enterprise, which is founded in 1998 in Shenzhen, China. As one of the most famous companies in China, Tencent believes in a great mission that endeavors to "improve the quality of life through internet value-added services" and insist the "user oriented" business philosophy which succeeds to absorb more than 1 billion costumers and over 30,000 employees. In order to follow the trend of economy and society, to run the company more effectively, Tencent always pays attention to HRD, since its establishment. Tencent focuses on optimize employees to give the most value and has always attached great importance to the training and development of its employees. Besides providing a professional learning platform, it also follows a relatively perfect training mechanism [3].

In the following parts of this paper, related literature and the specific case of Tencent will be shown. In addition, the documentary method will be involved in this paper. At the bottom of this article, conclusion and recommendation will be presented.

\section{Literature Review and Official Documents of Tencent}

\subsection{Related Literature Review}

With the development of economy, companies realize the increasing importance of the human resources. It is widely believed that optimal human resources can 
help companies to gain advantages in competition and enhance performance [4]. It can be suggested that human resource has a positive correlation with company performance [5]. To follow the dramatically changing of society and economy, HRM of companies is expected to be updated. According to former research, it is important to note that HRD is different from HRM. HRM pays attention to maintenance, while HRD focuses on education [6]. HRM is like a standalone operation that works to promote effectivities within the companies including administrative tasks such as files, paperwork, and payroll. By contrast, HRD works throughout an organization and be involved in various aspects of its working [7].

HRD has been defined as "a process of developing and unleashing human expertise through training and development and organization development for the purpose of improving performance" [8]. In addition, HRD also can be defined as "a set of systematic and planned activities designed by an organization to provide its members with the opportunities to learn necessary skills to meet current and future job demands [9]" which focuses on training, education and other types of development for workforce after they are employed by a company.

It can be stated that activities of HRD provide the necessary on-the-job skills for employees in all departments, which tend to increase production. It also helps employees feel the investment of the organization and their growth to creates a more loyal and efficient workforce. In addition, when workers regularly receive human resource development activities, they are more willing to accept change which means that employees can gain improvements from new practices rather than feeling threatened or worried [10]. Furthermore, people feel better when they get positive opportunities and are interested in, that is the fact that staff is proud of their work and organization [11]. Nevertheless, human resources continuously providing the right training can achieve an efficient workflow and more satisfied employees to increase productivity and customer service. Human resource managers are required to be intelligent, knowledgeable, skilled in HRM and organizational behavior, to learn and lead learning organizations, to create human capital not as authoritative leaders over them [12]. Successful organizations understand the need to maximize all of their resources-physical, financial, information and human. When employees perform better, companies perform better. HRD professionals help organizations maximize their human capital through training and organization development initiatives. Companies ought to consider human capital from individual perspective including employability, performance, career development, and organizational perspectives, which includes investment, ownership, skills and knowledge management. Highlight the implications for human resource development, both at individual and organizational levels [13].

In addition, it is believed that innovation in human resources is extremely significant for the development of companies [14]. This point can be improved that human capital, sufficient training programs, and competitive compensation and reward systems of a company help achieve its goals and strategies in the 
long run [15]. Furthermore, training and education offered by human resource departments have been paid attention by professional human resource managers and researchers [16]. Companies are expected to offer education and training opportunities to their employees, in order to improve skills and efficiency. Similarly, another research shows that technical employees play an increasingly important role in updating productivity, so, HRD ought to tend to provide employees with effective training and education which are beneficial to the development of both workforce and company [17].

\subsection{Official Documents of Tencent}

Tencent is founded by Ma Huateng in 1998, in Shenzhen city of China, as an internet service company. Now, it has been one of the largest Internet integrated service providers with the largest number of service users which achieve almost 1 billion in China. A new round of overall strategic has been upgrading to extend its advantage in consumer Internet and grasp the opportunities brought by the industrial Internet. This strategic upgrade will help Tencent drive the convergence of future social, content and technology trends for businesses and consumer service. Tencent is the first Chinese Internet published company in Hong Kong Stock Market. Because of its huge mass base, the diversification of Tencent achieves great success, the profit break $¥ 10$ billion at the ending of 2009. The year of 2011 is another milestone of Tencent, WeChat is launched. It not only consolidates Tencent's social leadership in the mobile field but also enhances the penetration rate of high-end smartphone users. Tencent's strength lies in its user's social graph, multi-platform marketing capabilities, infrastructure support, payment solutions and insights into user demand insights. Tencent has distributed 6 business groups, WeiXin Group, Interactive and Entertainment Group, Platform and Content Group, Cloud and Smart Industry Group, Corporate Development Group and Technology and Engineering Group, to develop business service [3].

In the fiscal year 2018 , revenues increase to $¥ 313$ billion which climbs by $32 \%$ year-on-year, primarily driven by financial services, social and video advertising, and digital content subscriptions and sales. Operating profit is almost $¥ 80$ billion increased by $8 \%$ year-on-year. Profit attributable to equity holders of the company increases by $10 \%$ year-on-year [3].

Since the establishment of Tencent, HRM and HRD have been paid extreme attention to, which means that Tencent focuses on organization structure, human resource planning, recruitment, and configuration, training and development, performance management, compensation management and organization culture.

You may note peculiarities. For example, the head margin in this template measures proportionately more than is customary. This measurement and others are deliberate, using specifications that anticipate your paper as one part of the entire journals, and not as an independent document. Please do not revise any of the current designations. 


\subsection{The Progress of HRD in Tencent}

In 1998, at the beginning of Tencent's establishment, due to the small number of employees, the human resources management function was relatively simple. The company did not set up an independent human resources management department.

In 2003, the number of employees of Tencent continued to expand, and Tencent officially established the Human Resources Department. The concept that "employees are the first wealth of the enterprise" has begun to gain popularity.

In 2007, the first corporate university in China's Internet industry-Tencent Academy was established, on September 10th. With the core goal of cultivating more talents, Tencent is committed to building a learning organization with Tencent's characteristics.

In 2010, the HR three pillar model has been used in Tencent.

In order to follow the trend of the new era, HRD in Tencent can be concluded by informatization, datafication, and "platformization" which will be detailed presented in Chapter 4.

\section{Methodology}

This paper can be classified as descriptive research which can be defined as a research method that describes the characteristics of the population or phenomenon that is being studied. This methodology focuses more on the "what" of the research subject rather than the "why" of the research subject. In another word, it primarily focuses on describing the nature of a demographic segment, without focusing on "why" a certain phenomenon occurs. In other words, it "describes" the subject of the research, without covering "why" it happens. The characteristics of this paper are quantitative, a cross-sectional study with uncontrolled variables, and a basis for further research.

In addition, the documentary method is involved in this paper, which can be defined as the use of outside sources, documents, to support the viewpoint or argument of an academic mission. The process of documentary research often involves some or all of conceptualizing, using and assessing documents (Scott 2006). The key issues surrounding types of documents and the ability to use them as reliable sources of evidence on the social world must be considered by the author who uses documents in this research [18].

\section{HRD Presentation and Analysis of Tencent}

\subsection{Introduction of Tencent's HR Three Pillar Model}

In Tencent, the human resource requirements from inside departments can be regarded as customer-oriented. The HRD of Tencent can be defined as the gradual development from purely transactional management or functional management to three roles of affairs, functions, and strategy. In 2010, the Human Resource of Tencent can be distributed into 3 parts, Human Resource Business 
Partner (BP), Human Resource Centre of Expertise (COE) and Human Resource Shared Service Centre (SSC) which are issued by Dave Ulrich in 1996 and firstly utilized by IBM. In 2013, the SSC has been replaced by Human Resource Shared Delivery Centre (SDC) to achieve more effective human resource service in Tencent [1].

\section{2. $\mathrm{COE}$}

In general, COE is think-tank and expert support section of Tencent's HR system, mainly responsible for front-line research, participate and interpret the company business strategy, formulate the company's HR tactics, and formulate relevant systems and policies. COE of Tencent including the HR Department, Tencent Academy, Remuneration and Welfare Department, and Corporate Culture and Employee Relations Department, is not an entity department, but rather a collection of several functions in human resource management. The COE is responsible for strategy and policy in employment, training and development of employees, establishing an effective labor system, stimulating employees' enthusiasm, formulating performance, and welfare system, paying attention to employees' feelings and building harmonious company atmosphere and corporate culture. In summary, these functional departments design business-oriented and innovative HR management policies, processes and solutions. And provide a company with customized HR solutions suitable for the business, with the help of their profound expertise and mastery of leading practices in the field [19].

\subsubsection{Employees' Training and Education}

Tencent Academy has been established to train employees with professional skills technology, and leadership. Two kinds of employee development pathways can be provided by COE.

It can be concluded that rookie employees have 2 pathways to promote in Tencent professional technical employees can go through foundation, professionals, senior and authority (Figure 1). Management employees can promote by junior, middle, and senior management. Different employees with various characteristics will have a different career.

To be specific, Tencent Academy plays a key role in COE, which is established in 2007. Tencent Academy endeavors to train and educate employees including management training, career training, orientation training, training management \& online learning platform, and lecturer \& course management.

There are some key points for training and education. The first point is that Tencent Academy needs to have interesting and useful learning content. For education, content is always king. Secondly, the form of training should be in the form of socialization, which is conducive to his sharing and recommendation. The third is that as training education and practitioners, Tencent Academy must study the user's preferences to guide and guide our training. The last one is the way people learn. In summary, Tencent Academy provides a variety of training 


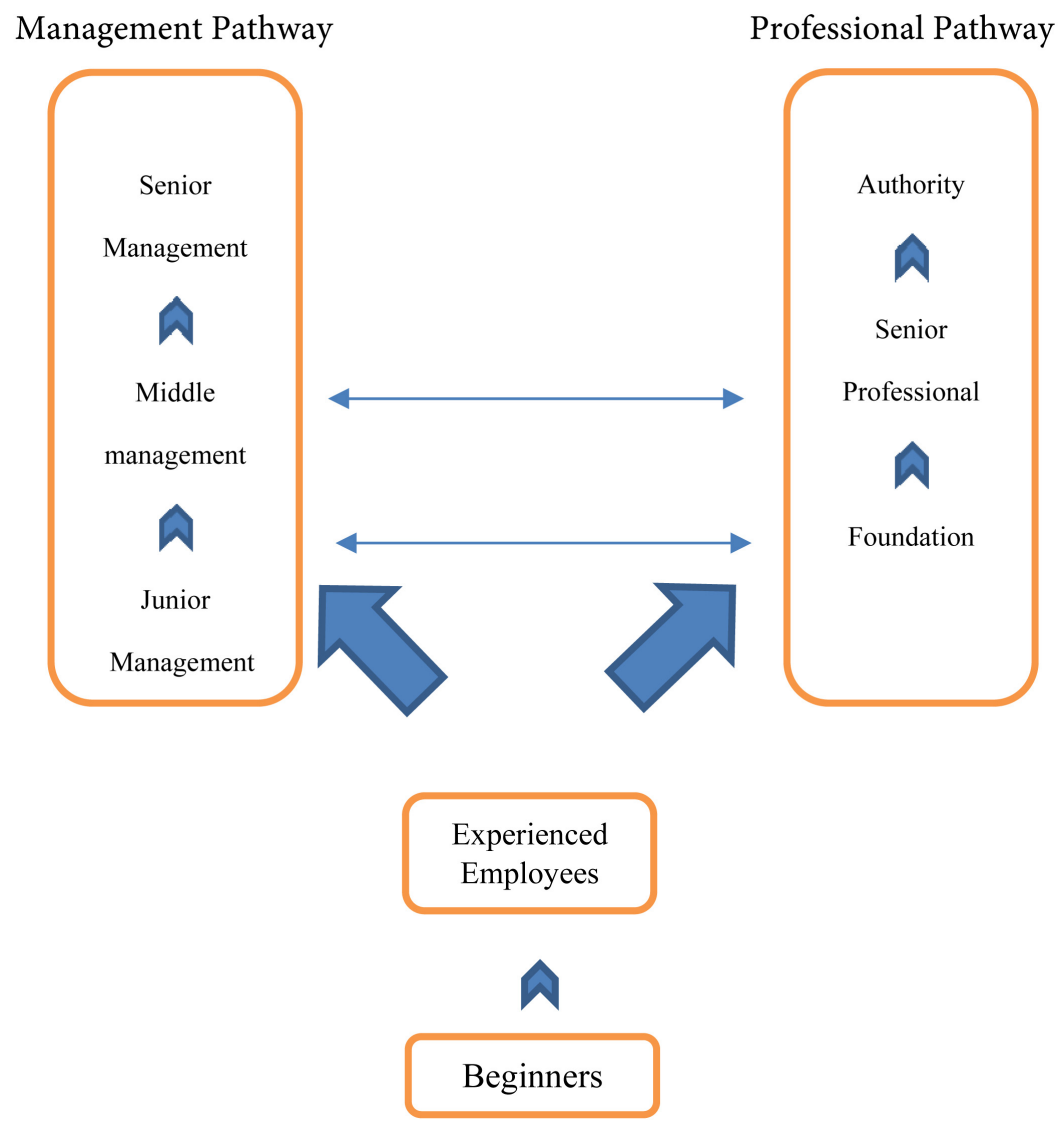

Figure 1. Two development path way provided by company (source from Tencent.com).

and courses for its employees to develop employee's talents for their benefit and for the benefit of Tencent's present and future [20].

\subsubsection{Corporate Culture and Employee Relationship}

Furthermore, Corporate Culture and Employee Relations Department has some main functions. Tencent believes that the best practice is not to rely on people, nor policy, but on culture. Tencent's Culture has experienced the process of transforming from home culture to professional competition culture. The COE Corporate Culture and Employee Relations Department took the lead in this change. Enterprises must make employees aware of their duties and responsibilities at the first time, and realize that enterprises are not the place to enjoy comfort but a large family of professional employees. Such a corporate culture can make people and the company develop [21].

Tencent pays attention to the relationship between employees and organization, but it is extremely difficult to make effective communication with over 30,000 employees. After some attempts, the department found that passive communication has little effect, and the active participation of employees brings unexpected gains. Employees discuss the strategic direction by participating in hot topic interactions and quickly keep information with enterprises on key issues. It is widely believed that an open and transparent atmosphere is important. 


\subsubsection{Remuneration and Welfare}

In addition, the Remuneration and Welfare Department endeavors to establish a compensation system with internal fairness and external competitiveness to attract, retain and motivate the company's talents. To create a company's "performance-oriented" compensation philosophy by implementing remuneration and welfare policy that reflects job value and employee performance. Remuneration of employees includes regular wage, annual bonus, performance bonus, special purpose fund, and stock equity. For instance, on 11, Nov 2016, the 18th anniversary of Tencent, 300 shares for each Tencent employee, which values 1.7 billion HKD [22]. In addition, Tencent launches more than 370 employee-bus in Shenzhen city, cover 1000 bus stops and continuous operate more than 7 hours per day, which is like a bus system is a medium city. Each employee has 30-day leaves per year [23].

In summary, these functional departments of COE draw on the deep expertise in the field and master the leading practices, design business-oriented, innovative HRD policies, processes and solutions, and offer customized business HR solutions.

\subsection{BP}

Another crucial sector of HR three pillar is BP, which is regard as a business partner inside the company and asks more professional support from COE. In other words, to achieve business goals, cooperating with the internal customers of the company, thinking about how to help the business group achieve goals, building partnerships with them, gaining the trust of customers, and enabling them to take the initiative each time they encounter business problems. The BP department communicates and finds solutions to truly establish a business alliance. There are 6 business groups in Tencent, BP is the human resources system which distributes human resources management staff in the mentioned 6 business groups of Tencent. Therefore, to make the BP develop towards the business partners, it is necessary to reorganize the current HR work of the enterprise to make a more reasonable proportion of time, from reducing the transactional work, but increase the time investment of tactical and strategic work. Another one of the most important requirements is to solve practical needs in business, such as increasing market share and reducing production costs. For BP to become a business partner, this is the key first step. Without clear business needs, there is no method of how to support the business. Therefore, BP must think in terms of business, configure personnel according to effective standards, and at the same time, do a good job in recruitment, training, compensation, performance, and labor. This involves employee satisfaction and engagement. For the needs of employees in different business groups, HR cannot passively wait for internal staffs to propose human resources requirements. Instead, the professional value of human resources must be actively exerted. BP is required to implement and promote the company's human resources management policies in various business departments, help business sectors to cultivate and develop 
human resource management capabilities to improve business performance. Furthermore, BP needs to understand the business of the 6 groups, and be able to provide professional solutions tailored to the individual needs of the business unit, truly embedding human resources and its value into the value modules of each business unit.

In addition, BP is required to have some common capabilities including communication skills, problem-solving skills, teamwork, and customer orientation; some expertise including HR general expertise, general industry knowledge and related legal knowledge; some professional skills including requirements analysis and management and resource integration capabilities; and influence in organizational behavior including methodology construction, knowledge transfer and talent development.

\subsection{SDC}

The SDC of Tencent is updated from SSC in 2013. The background is due to the fact that if human resource is expected to participate in and drive the strategy of enterprise development, a long-term system, which can sustainably support strategy requirements, is necessary. To be specific, business needs have changed from early stability requirements to versatile requirements, and HRM has more emphasis on flexibility. Secondly, it is the new needs of employees' personalization and self-management and it is necessary to study human nature. The SSC can be defined as a platform with centralized and standardized services shared by the group and provide COE and BP with high quality, low cost. The SDC can be described as a productized, systematic and information-based shared delivery platform which integrates the common needs of the group and provide a one-stop overall solution that exceeds expectations for business, employees and HR partners. SDC is expected to share resources, capabilities, teams, and information through new organizations, new attributes, new pattern, new tools, and new capabilities and actively explore and integrate various common needs in the HR field. The traditional SSC only concentrates all the administrative affairs related to HRM in each business unit of the enterprise group and establishes a service center. One of the most prominent features of SDC's upgrade is the emphasis on "platformization" [24]. The term "platformization" mentioned here not only refers to the development of information technology, but also enhances SDC's product attributes, user attributes, and fun attributes. SDC can connect every sector and make the connection gradually platformed, systematic, and continuous. Tencent attempts to separate the entire SDC back-office center into five product centers, talent transportation, business ability, employee satisfaction, solving systematic issue and human outsourcing service platform. In summary, SDC is the upgrade of work values and motivations which means that the HR department takes the initiative to understand the needs of the business department and proactively provide service plans. In addition, the service target is extended from HR to full staff. 


\subsection{Analysis-Relationship between COE, BP and SDC}

The relationship between $\mathrm{BP}, \mathrm{SDC}$, and $\mathrm{COE}$ is like a triangle. $\mathrm{COE}$ is evidence and guidelines for SSC, which means that after the COE has formulated the human resources strategy, system and policy, the specific work needs to be implemented and refined by the SSC, and the human resources management work will be done meticulously. In the process of SSC's work, the feedback of issues can be reacted to $\mathrm{CEO}$ to formulate a more effective policy and system. Furthermore, under the policy and strategy from COE, BP has responsibilities to refining and optimizing to satisfy different requirements from various business groups. Some issues and suggestions will be responded to COE to formulate a more advanced policy and strategy. On the one hand, $\mathrm{COE}$ can formulate new recruitment to find suitable talents. On another hand, COE trains and cultivates their employees to develop advanced. Then, COE provides BP with professional support to manage HR better and delivers policy and formulation to SDC. SDC has responsibilities to execute basic HR management for business groups based on COE's policy and BP's feedback.

\section{Findings and Conclusions}

HRD is crucial for the development of a company, not only the responsibility of the HR department, but also a co-operation between HR and business groups. With the intensification of competition, the role of talents is becoming increasingly prominent. The human resources management of enterprises must be strategically forward-looking and dare to help or influence the company's senior management to formulate plans and decisions from a professional perspective. Furthermore, in the process of enterprise development, not only technological innovation can bring huge economic benefits to enterprises, but also insist on management innovation and release the management enthusiasm of enterprises. Moreover, different business groups, departments and employees have different requirements, and there may be contradictions between them. HR must have the knowledge of the business, establish a customer-and product-oriented mindset and meet the needs of each business unit and employees. HR also promptly resolve the contradictions between internal departments and employees to become a strong guarantee for talent stabilization. The original HRM only emphasizes the organizational structures from the perspective of the organization. The new SDC, COE, BP not only explore from within the organization but also emphasize the technology, business, and organizational change, from the perspective of people and the environment. The new model is positive to the interaction of talents. The expansion of the new perspective has promoted the breakthrough and innovation of the three pillars of Chinese enterprises and injected new vitality into the transformation of the organizational structure of enterprises.

In addition, the organization should pay attention to the construction of strategic human resource management and attach importance to the strategic role of COE. HRD should match organizational strategy and corporate culture. It in- 
fluences individual behavior through corporate culture. The three together determine the employee's autonomous behavior, which in turn affects employee performance, and corporate financial performance, and ultimately affects the market value of the enterprise.

\section{Recommendation}

With the HRD of Tencent, HR talents are important to the company. Therefore, for the selection of human resources talents, the organization ought to not only pay attention to its professionalism but also be familiar with the company's strategy and operation. Its focus is not only on the professionalism of the field but also on the familiarity with the business. Therefore, in the construction of COE, BP, and SDC cooperation mechanisms, enterprises should promote the communication and exchange between COE experts and HRBP and SSC, and coordinate the training of HR talents.

Any service provided by HR should be embodied in the form of a product. When turning any work into a product, you can quickly respond to users' feedback and requirements through the operating system to improve service quality and efficiency.

Finally, HRD should fit the corporate strategy. Because the role of talents is increasingly prominent, the human resources management of enterprises must be strategically forward-looking and dare to help or influence the company's senior management to formulate plans and decisions from a professional perspective. HRD ought to adhere to innovation, in the process of enterprise development, not only technological innovation can bring huge economic benefits to enterprises, but also insist on management innovation and release the management energy of enterprises. HR needs to establish the concept of customers and products. In the operation of enterprises, different business groups, departments, and employees have different needs, and there may be contradictions between them. Human resource managers must have the knowledge of the business, establish a customer-and product-oriented mindset, have the awareness of product managers, better meet the needs of each business unit and employees, and also promptly resolve the internal departments and employees.

\section{Conflicts of Interest}

The authors declare no conflicts of interest regarding the publication of this paper.

\section{References}

[1] Zhang, X.R., Fang, Z.F. and Tao, X.B. (2015) Application and Challenge of Big Data in Human Resource Management. Human Resources Development of China, 22, 51-57. (In Chinese)

[2] Becker, B. and Huselid, M. (2006) Strategic Human Resources Management: Where Do We Go from Here? Journal of Management, 32, 898-925.

https://doi.org/10.1177/0149206306293668 
[3] Tencent (2018) Annual Report of Tencent.

[4] Fleetwood, S. and Hesketh, A. (2010) Explaining the Performance of Human Resource Management. Cambridge University Press, Cambridge.

https://doi.org/10.1017/CBO9780511781100

[5] Kesti, M. (2012) Organization Human Resources Development Connection to Business Performance. University of Lapland, Rovaniemi. https://www.sciencedirect.com/science/article/pii/S221256711200086X https://doi.org/10.1037/e582902013-002

[6] Maier, A., Brad, S., Nicoară, D. and Maier, D. (2014) Innovation by Developing Human Resources, Ensuring the Competitiveness and Success of the Organization. Procedia-Social and Behavioral Sciences, 109, 645-648. https://doi.org/10.1016/j.sbspro.2013.12.521

[7] Garavan, T.N., Morley, M., Gunnigle, P. and Collins, E. (2001) Human Capital Accumulation: The Role of Human Resource Development. Journal of European Industrial Training, 25, 48-68. https://doi.org/10.1108/EUM0000000005437

[8] Swanson, R. (1995) Human Resource Development: Performance Is the Key. Human Resource Development Quarterly, 6, 207-213.

https://doi.org/10.1002/hrdq.3920060208

[9] Werner, J. and DeSimone, R. (2012) Human Resource Development. South-Western, Mason.

[10] Tripon, A. (2014) Innovative Technology for Sustainable Development of Human Resource Using Non-Formal and Informal Education. Procedia Technology, 12, 598-603. https://doi.org/10.1016/j.protcy.2013.12.535

[11] Oscar, A.A. (2001) Proceedings AHRD 2001 Conference, Academy of Human Resources Development.

[12] Mulang, A. (2015) The Importance of Training for Human Resource Development in Organization. Journal of Public Administration and Governance, 5, 190-191. https://doi.org/10.5296/jpag.v5i1.7505

[13] Garavan, T.N., Morley, M., Gunnigle, P. and McGuire, D. (2002) Human Resource Development and Workplace Learning: Emerging Theoretical Perspectives and Organisational Practices. Journal of European Industrial Training, 26, 60-71. https://doi.org/10.1108/03090590210428133

[14] Demirkaya, H., Özcüre, G. and Eryiğit, N. (2011) An Application on the Impacts of Human Resource Management in Technology Management of the Companies. Procedia-Social and Behavioral Sciences, 24, 474-486. https://doi.org/10.1016/j.sbspro.2011.09.045

[15] Zehir, C., Gurol, Y., Karaboga, T. and Kole, M. (2016) Strategic Human Resource Management and Firm Performance: The Mediating Role of Entrepreneurial Orientation. Procedia Social and Behavioral Sciences, 235, 372-381. https://doi.org/10.1016/j.sbspro.2016.11.045

[16] Bo, M. (2018) Implementing Change through Human Resource Development. Doctoral Dissertation, Financial College of Dalian, Dalian. http://www.lixianfc.com/fanwen/611.html

[17] Buchari, E. and Basri, H. (2015) The Importance of Human Resources Development and Its Impact in Increasing of National Port Productivity. Procedia Engineering, 125, 519-525. https://doi.org/10.1016/j.proeng.2015.11.049

[18] Scott, J. (2006) Documentary Research. Sage Publications Ltd., London. https://doi.org/10.4135/9781446261422 
[19] Xi, N., Li, Y., Peng, J. and Ma, H.G. (2017) Evolution from Informationized Human Resource Management to Big Data Human Resource Management. Human Resources Development of China, 5, 79-87. (In Chinese)

[20] Tencent (2018). https://www.tencent.com/en-us/culture.html

[21] Huang, Y.L., Rong, S. and Liu, Z.Y.A. (2018) Research on the Internal and External Fit of Strategic Human Resource Management, Organizational Strategy and Enterprise Culture-A Case Study of Tencent's COE. Human Resources Development of China, 35, 72-80. (In Chinese)

[22] https://news.mydrivers.com/1/507/507304.htm

[23] Hrsee (2019) Tencent Case Study: High Welfare, Good Treatment Brought by the Malady. http://www.hrsee.com/?id=928

[24] Ma, H. (2015) The New Ecology of Tencent HR SDC in the Mobile Internet Era. Human Resources Development of China, 18, 6-11. (In Chinese) 